ISSN: 2162-3104 Print/ ISSN: 2166-3750 Online

Volume 8, Issue 4 (2018), pp. 1522-1548

(C) Journal of International Students

http://jistudents.org/

doi:10.5281/zenodo. 1467807

\title{
Stress-Driven Spending: Correlates of International Students' Adjustment Strains and Compulsive Online Buying
}

\author{
Yana Lou \\ Auburn University, USA \\ Sang-Eun Byun \\ University of South Carolina, USA
}

\begin{abstract}
We investigated international students' stress-driven spending behavior by focusing on the psychological and behavioral consequences of the strains they experience during the adjustment process in the U.S. We found that certain adjustment strains significantly lowered international students' selfesteem, which further affected their happiness and engagement in compulsive online buying. This study highlights the importance of understanding underlying drivers and consequences of international students' adjustment strains to facilitate better adaptation to a foreign culture and to prevent negative consumption tendencies.
\end{abstract}

Keywords: adjustment strains, compulsive online buying, happiness, international students, self-esteem

Approximately 1.04 million international students studied at U.S. colleges and universities during the 2015-2016 academic year (National Association of Foreign Student Advisers, 2016), an increase of $72 \%$ over the past 15 years (Institute of International Education, 2015). The top ten sending countries are China, India, South Korea, Saudi Arabia, Canada, Japan, Vietnam, Taiwan, Mexico, and Brazil (U.S. Immigration and Customs Enforcement, 2015). International students bring great economic benefits to 
American society and universities, spending \$27 billion in 2015 (Institute of International Education, 2015). However, international students often face adjustment problems, mainly due to differences in language, educational systems, and social norms, as well as homesickness, financial problems, and sometimes racial discrimination (Gareis, Merkin, \& Goldman, 2011; Wehrly, 1988). Although researchers have studied international students' adjustment strains, little is known about how these strains affect students' shopping and spending. The literature suggests that a sense of social rejection, low self-esteem, unhappiness, and other negative feelings experienced during the adaptation process significantly alter consumption and spending behavior (Baumeister, DeWall, Mead, \& Wohs, 2008). Although consumers may shop as a coping strategy to temporarily relieve their negative mood (Atalay \& Meloy, 2011), repetitive stress-driven consumption may promote compulsive buying, thus generating long-term negative consequences (Roberts \& Jones, 2001).

Therefore, understanding underlying drivers and consequences of international students' adjustment strains is critical to facilitate better adjustment to U.S. culture and to prevent negative consumption tendencies. To address this gap in the literature, we examine (1) the extent to which international students' adjustment strains influence self-esteem and happiness and (2) how these factors (adjustment strains, self-esteem, and happiness) affect compulsive online buying. Given the increasing consumption power, population size, and societal influence of international students in American colleges and universities (Jordan, 2015), the finding of this study will provide important implications for developing policies or programs for international students in higher education in the U.S.

\section{LITERATURE REVIEW}

\section{International Students' Adjustment Strains}

International students' adjustment strains (ISAS), also known as acculturative stressors, are defined as the everyday problems that international students contend with when living in foreign countries (Crano \& Crano, 1993). Previous studies have identified four major sources of adjustment strains for international students in higher education: academic strains, language strains, personal strains, and social strains (Chen, 1999; Crano \& Crano, 1993; Gebhard, 2012; Smith \& Khawaja, 2011).

Academic strains, or problems related to schooling, are a significant predictor of life stress (Smith \& Khawaja, 2011). ISAS related to education factors mostly come from adjusting to American education systems (e.g., 
different teaching styles), concerns about poor academic performance, and different relationship patterns between teachers and students, problems which can result in lowered confidence (Crano \& Crano, 1993; Smith \& Khawaja, 2011). Academic stains for some international students may also be intensified by high familial expectations, and academic failure affects international students' self-esteem and psychological well-being (Mori, 2000). Because most international students invest considerable effort and financial resources in studying abroad, the pressure of high expectations from self and family and a sense of academic failure negatively influence happiness (Liu \& Winder, 2014; Lu \& Gilmour, 2006).

Furthermore, international students often face difficulties in finishing assignments on time, understanding lectures, and expressing their thoughts (Gebhard, 2012; Smith \& Khawaja, 2011). Because language is a key factor interrelated with many academic and sociocultural strains, language barriers and continuous communication difficulties can lead to psychological distress, reducing students' self-esteem, making them insecure, and inhibiting social interactions (Barratt \& Huba, 1994; Chen, 1999). Worse, language barriers create a negative cycle: the poorer international students' English skills are, the less they want to interact socially, so that their English skills do not improve and they feel still more adjustment strains (Chen, 1999).

Personal strains involve personal experiencing of negative feelings (Crano \& Crano, 1993). International students tend to have less successful friendships with Americans due to problems with communication and language (Gareis et al., 2011). Less successful friendships, in turn, contribute to loneliness and homesickness (Smith \& Khawaja, 2011) and further depression (Wehrly, 1988).

Social strains involve negative feelings experienced in social life, such as feelings of isolation, rejection, exclusion, and discrimination (Crano \& Crano, 1993). Many international students feel rejected, excluded (EdwardsJoseph \& Baker, 2012; Liu \& Winder, 2014; Searle \& Ward, 1990) or discriminated against (Poyrazli \& Lopez, 2007). According to social identity theory, an individual's identity derives from knowledge of his/her belonging and identifying with a certain social category (Tajfel, 1978). International students can be considered a minority group, but since most were not regarded as members of a minority group before coming to the U.S., most of them have little experience with minority group identification (Schmitt, Spears, \& Branscombe, 2003). As a result, international students often experience identity conflicts, a key source of culture shock which can trigger feelings of sadness, anger, low self-esteem, and defensiveness (Kim, 
2001). Perceived devalued identity further affects happiness by lowering self-esteem (Roccas, Horenczyk, \& Schwartz, 2000). Another major social concern among international students is strains from dating practices and male/female relationships (Poyrazli \& Kavanaugh, 2006; Yi, Lin, \& Kishimoto, 2003). International students are likely to have lower confidence in their self-esteem and to experience unhappiness when they struggle with social relations with significant others, when they feel uncomfortable with social interactions, or when they are confused about morals and sexual customs in a foreign culture.

\section{Self-Esteem and Happiness}

Self-esteem, which can be global or domain-specific, is defined as individuals' attitudes toward their own value and worth as a person (Rosenberg, Schooler, Schoenbach, \& Rosenberg, 1995). Rosenberg et al. (1995) found that global self-esteem is more strongly related to aspects of psychological well-being such as happiness, while specific domains of selfesteem (e.g., academic self-esteem) are more strongly related to behavior outcomes (e.g., academic performance). This study examines how international students' adjustment strains influence global self-esteem and further affect overall happiness. Studies have found that students who are psychologically distressed during the adjustment process tend to show lower self-esteem than students who are well-adjusted (Wang et al., 2012).

Happiness has been defined as subjective well-being ( $\mathrm{Lu} \&$ Gilmour, 2006) and has been described based on aspects of life satisfaction, momentary pleasures, or positive subjective experiences (Flynn \& MacLeod, 2015). Many studies have found that self-esteem is a significant predictor of psychological well-being (Furnham \& Cheng, 2000; Nesdale \& Mak, 2003; Rosenberg et al., 1995). In particular, Furnham and Cheng (2000) found that self-esteem was the most dominant and powerful predictor of happiness among young consumers. Thus, when international students have impaired self-esteem from adjustment strains, they are likely to experience less happiness.

\section{Compulsive Online Buying}

Compulsiveness has generally been regarded as a psychiatric disorder (O'Guinn \& Faber, 1989) or as a lack of impulse control (Billieux, Rochat, Rebetez, \& Van der Linden, 2008; Christenson et al., 1994). O'Guinn and Faber (1989) defined compulsive buying as "a response to an uncontrollable drive or desire to obtain, use or experience a feeling, substance, or activity that leads an individual to repetitively engage in a behavior that will 
ultimately cause harm to the individual and/or others" (p. 148). Christenson et al. (1994) defined compulsive buying as repeated, uncontrolled, and excessive impulsive buying behavior which leads to problems such as debts, family conflict, and guilty feelings.

Gronmo (1988) argued that people who perceive psychosocial deficiencies may engage in shopping to compensate for these deficiencies and the lack of self-esteem or self-actualization may explain the underlying mechanism of compensatory consumption behavior. Thus, later researchers combined the phenomenon of compulsive buying with other social psychological concepts, such as materialistic values, and viewed compulsive buying as compensatory behavior to improve self-image, self-esteem, or relationships with others (Dittmar, 2005).

Studies have found that younger people (Dittmar, 2005) and people with negative mood (Billieux et al., 2008) tend to engage in compulsive buying. Furthermore, compulsive online buying has risen among young adults along with the widespread use of mobile devices (Manchiraju, Sadachar, \& Ridgway, 2016). Consumers with higher compulsive buying tendencies tend to engage in online buying (Kukar-Kinney, Ridgway, \& Monroe, 2009). Daily deals available on websites urge compulsive online buying by increasing time or social pressures (Kukar-Kinney, Scheinbaum, \& Schaefers, 2016). However, compulsive online buying has negative consequences, such as overspending or control disability, thereby harming one's physical and mental health, social and financial well-being (Dittmar, Long, \& Bond, 2007).

\section{Drivers of Compulsive Buying}

According to symbolic self-completion theory, people's activities are intended to substantiate their definition of themselves, a definition that can indicate their identity (Gollwitzer, Wicklund, \& Hilton, 1982). People with feelings of powerlessness or low self-esteem tend to look for high-status products to compensate themselves (Rucker \& Galinsky, 2008) or to buy things to make themselves feel more worthy (Kukar-Kinney, Ridgway, \& Monroe, 2012). Stress, negative mood, and low self-esteem are positively associated with compulsive buying behavior. For example, O'Guinn and Faber (1989) found that people with compulsive buying tendencies tend to have lower self-esteem and the ability to fantasize, which helps them forget about personal problems caused by low self-esteem. Hanley and Wilhelm (1992) further stated that compulsive consumers have a stronger belief that money can enhance self-esteem than do those with normal consumption behavior. Accordingly, compulsive buyers tend to display high intention to 
buy prestige products to increase their self-worth and self-completion (Kukar-Kinney et al., 2012). Stress and anxiety may motivate compulsive buying (DeSarbo \& Edwards, 1996). In a similar vein, Rick, Pereira, and Burson (2014) found that sadness, which is associated with an individual's feeling of lack of personal control over the environment, can be significantly alleviated through shopping because shopping restores a sense of control during the selection process. Therefore, international students' feelings of stress, rejection, and lack of control may lead to low self-esteem and unhappiness (Crano \& Crano, 1993; Fisher \& Hood, 1987). Such psychological impairments may influence international students to shop to improve their mood and self-esteem.

Accordingly, the following hypotheses are proposed:

$\mathrm{H}_{1}$ : The higher the ISAS (a. academic, b. language, c. personal, and d. social strains), the lower international students' selfesteem.

$\mathrm{H}_{2}$ : The higher the ISAS (a. academic, b. language, c. personal, and d. social strains), the lower international students' happiness.

$\mathrm{H}_{3}$ : The lower international students' self-esteem, the lower their happiness.

$\mathrm{H}_{4}$ : The lower international students' self-esteem, the higher their engagement in compulsive online buying.

$\mathrm{H}_{5}$ : The lower international students' happiness, the higher their engagement in compulsive online buying.

$\mathrm{H}_{6}$ : The higher the ISAS (a. academic, b. language, c. personal, and d. social strains), the higher international students' engagement in compulsive online buying.

\section{RESEARCH METHOD}

\section{Data Collection}

International students enrolled at a major southeastern university were selected as a convenience sample for this study. As of Spring 2016, this university had 1,639 international students (male $=1,059$, female $=580$ ), including 514 undergraduate students, 1,123 graduate students, and two professional students. The top sending countries were China, India, Brazil, South Korea, Bangladesh, Saudi Arabia, Turkey, and Iran. The data were 
collected using Qualtrics, an online survey. The International Students Organization electronically distributed the survey to their email list of 1350 students. International students who were at least 19 years old and who had studied at least one semester in the U.S. were eligible for this study. Students who had studied less than one semester were excluded from this study because their self-esteem and happiness were less likely to be significantly affected by the strains experienced in a short time period. In total, 210 subjects clicked on the survey (response rate $=15.56 \%$ ). After eliminating one ineligible, 56 incomplete and seven straight-lining responses, a total of 146 responses were usable for analysis. Twenty participants were randomly drawn to receive $\$ 25$ store gift cards.

\section{Instruments}

The survey questionnaire was developed by modifying existing scales. For ISAS, 28 out of 38 items in Crano and Crano's (1993) scale were used. The questions about relationships with host families and concerns with food differences and health problems were excluded because most university students live in dorms or apartments rather than living with host families and more dietary options are available now than in 1993. The original items were slightly modified to measure adjustment strains experienced in the U.S. In addition, the verb "trouble" was replaced with the verb "distress" to suggest the level of strains experienced. Seven items were used for academic strains; six for language strains; nine for personal strains; and six for social strains. The reported reliabilities for each scale were $.69, .86, .80$, and .73 respectively (Crano \& Crano, 1993).

Self-esteem was measured by the Texas Social Behavior Inventory scale, which includes 16 items (Helmreich \& Stapp, 1974). The reliability of the original scale was recently reported as .82 (Robins, Hendin, \& Trzesniewski, 2001). Happiness was measured by the five-item life satisfaction scale (Diener, Emmons, Larsen, \& Griffin, 1985). The reported reliability of the original scale was .87 . The life satisfaction scale was adopted because the study examined the overall happiness (i.e. subjective well-being) of international students. The scale was slightly modified to include "in the U.S." in each item.

To measure engagement in compulsive online buying, d'Astous, Maltais, and Roberge's (1990) eleven-item compulsive buying scale was used. The scale was modified to reflect the context of online shopping (e.g., "I bought a product online that I did not need even when I knew I had very little money left"). In addition, the items were modified from the present tense to the past tense to measure the participants' actual behavior, rather 
than motivation or behavioral tendency. The original scale had the reported reliability of .78. Given their correlation with compulsive buying, materialism (Dittmar, 2005) and impulsive buying tendency (Billieux et al., 2008) were measured and tested as covariates of compulsive buying. Eight items were adopted from Trinh and Phau's (2012) materialism scale, including four items for material success (e.g., "I like to own things that make people think highly of me") and four items for material happiness (e.g., "Material possessions are important because they contribute a lot to my happiness"). The reported reliability ranged from .86 to .93 for material success and .81 to .86 for material happiness (Trinh \& Phau, 2012). Impulsive buying tendency was measured by Rook and Fisher's (1995) nine-item buying impulsiveness scale (e.g., "I often buy things spontaneously"). The reported reliability was .88 (Rook \& Fisher, 1995).

For all the scales above, seven-point Likert-type scales were used $(1=$ Strongly disagree and $7=$ Strongly agree; $1=$ Never and $7=$ Always for engagement in compulsive online buying). The survey began with two screening questions about age and the length of time spent in the U.S. Participants were also asked what year they came to study in the U.S. On the last page, they were asked about demographic characteristics including gender, nationality, class standing, and monthly income, which included assistantships and allowances from their family.

To determine whether international students could understand the survey, a pretest was conducted with non-native English speakers with low English proficiency, recruited from the personal network of the primary investigator. Seven international students (two undergraduate and five graduate) from China, South Korea, and Iran reviewed the questionnaire. Questions they found difficult to understand were revised with easier words or expressions. For example, several participants could not understand the word "treatment" in the question "the treatment I receive in the U.S. at social functions distresses me." Therefore, we changed the wording to "I am distressed because of the way other people speak to me and act toward me at social functions in the U.S." The participants were also confused by four items from the self-esteem scale: "I am a good mixer;" "I would describe myself as one who attempts to master situations;" "other people look up to me;" and "I make a point of looking other people in the eye." These items were revised to "I am good at approaching other people at social functions;" "I would describe myself as one who tries to feel in control of a situation;" "other people respect and admire me;" and "I always try to look straight at people when I talk to them." In the main test, a response box was provided on every page of the online survey where respondents could indicate any 
words or questions that confused them. Moreover, the instructions for the survey informed participants that they could use a dictionary while taking the survey.

\section{RESULTS}

\section{Sample Profile}

The age of the respondents ranged from 19 to $40($ mean age $=28.2)$ and $55.5 \%$ were male. The majority were graduate students $(85.6 \%)$ and had been in the U.S. fewer than five years $(80.80 \%)$. About $78.8 \%$ of the respondents were from Asian countries, including 39.0\% from China, 14.4\% from India, 4.8\% from South Korea, 4.8\% from Bangladesh, and 14.3\% from other Asian countries. The remaining respondents came from the Middle East (6.2\%), Europe (5.5\%), Latin America (4.1\%), Africa (3.4\%), and Oceania (1.4\%). About $24.7 \%$ had a monthly income (including assistantships and allowances from their family) of $\$ 501$ to $\$ 1000 ; 34.9 \%$ had \$1001 to \$1500; and 22.6\% had \$1501 to \$2000.

\section{Factor Analysis and Reliability}

Few respondents left comments about confusing words or questions. Therefore, all items were used for the next analysis. Exploratory factor analysis (EFA) was performed to explore the underlying structure of ISAS; self-esteem; happiness; compulsive online buying; and two covariates, materialism and impulsive-buying tendency. Principal components analysis (PCA) with varimax rotation was used. A Cronbach's $\alpha$ value of .70 or higher shows good reliability of the scale (Nunnally \& Bernstein, 1994).

EFA was run for ISAS. Cross-loaded items and items below .6 in the factor loadings were eliminated one by one. In total, nine items were dropped. Nineteen items were submitted to the next analysis: four for academic strains, six for language strains, four for personal strains, and five for social strains. Nineteen items confirmed the four dimensions (Table 1). The Cronbach's $\alpha$ s were $.78, .93, .86$, and .88 respectively for academic, language, personal, and social strains, showing the internal consistency of the items. The Eigenvalues ranged from 1.35 to 7.33 and the four dimensions explained $70.05 \%$ of the total variance. Language strains accounted for the highest variance, $38.59 \%$.

EFA was conducted for self-esteem and happiness (Table 2). The 5-item happiness scale was uni-dimensional (Eigenvalue $=2.35$, Total variance explained $=13.85 \%$, Cronbach's $\alpha=.87$ ). However, the 16-item self-esteem scale, which was reported to be uni-dimensional in the original study, 
showed three underlying dimensions in this study. Accordingly, each dimension was named based on the items loaded in each dimension. The first factor was named "social competence" and had six items, which explained $32.20 \%$ of the total variance. The second factor was named "social expression confidence" and had four items, which explained $12.27 \%$ of the total variance. The third factor was named "social dominance" and had two items, which explained $6.80 \%$ of the total variance. The Eigenvalues ranged from 2.09 to 5.47 . The self-esteem and happiness scales explained $65.11 \%$ of the total variance. The Cronbach's $\alpha$ s were above .70, except for social dominance, which was .62 .

Table 1. EFA results for ISAS.

Academic strains $(\alpha=.78 ; \mathrm{EV}=1.36 ; \mathrm{VE}=7.13 \%)$

Being unable to concentrate on my studies in the U.S. distresses

Factor

me.

Feeling uninterested in the university I am attending in the U.S. distresses me.

My concern with grades in the U.S. distresses me.

Relationships between teachers and students in the U.S. distress me.

Language strains $(\alpha=.93 ; \mathrm{EV}=7.33 ; \mathrm{VE}=38.59 \%)$

My difficulties in speaking English distress me.

I am distressed when I attend classes and lectures in English

because I don't understand English very well.

I am distressed when I read textbooks and novels written in

English because I don't understand them well.

Not being able to understand slang phrases in the U.S.

distresses me.

My limited English vocabulary distresses me.

Knowing that I need help with English distresses me.

Personal strains $(\alpha=.86 ; \mathrm{EV}=1.64 ; \mathrm{VE}=8.63 \%)$

Being lonely in the U.S. distresses me.

Feelings of homesickness in the U.S. distress me.

Frequently crying or feeling depressed in the U.S. distresses me.

Feeling that I would prefer to go home immediately distresses me.

Social strains $(\alpha=.88 ; \mathrm{EV}=2.98 ; \mathrm{VE}=15.69 \%)$

The relationship between men and women in the U.S. distresses 


\begin{tabular}{lc}
\hline Measurement item & $\begin{array}{r}\text { Factor } \\
\text { loading }\end{array}$ \\
\hline me. & .83 \\
The dating practices of people in the U.S. distresse me. & .86 \\
Sexual customs in the U.S. distress me. & .70 \\
I am distressed because I feel uncomfortable among groups of & .76 \\
people in the U.S. & \\
I am distressed because I feel confused about morals in the U.S. & \\
\hline
\end{tabular}

Note. $\mathrm{EV}=$ Eigenvalue, $\mathrm{VE}=$ variance explained.

Next, EFA was run for the 11 items of the compulsive online buying scale. The results confirmed the uni-dimensionality of the scale (Eigenvalue $=7.13$, Total variance explained $=64.79 \%$ ). All factor loadings were above .70 and Cronbach's $\alpha$ was .94. Lastly, EFA was run with materialism and impulsive buying tendency as covariates for compulsive online buying. The eight items turned out to be one dimension (Eigenvalue $=5.57$, Total variance explained $=69.61 \%$, Cronbach's $\alpha=.94$ ). Of the nine items for impulsive buying tendency, a reverse-coded item turned out to be in a different factor and was dropped. The final eight items confirmed the unidimensionality $($ Eigenvalue $=5.50$, Total variance explained $=61.04 \%$, Cronbach's $\alpha=.93$ ).

Table 2. EFA results for self-esteem and happiness.

\begin{tabular}{lc}
\hline & Factor \\
Measurement item & loading \\
\hline
\end{tabular}

\section{Self-esteem}

Social competence $(\alpha=.87 ; \mathrm{EV}=5.47 ; \mathrm{VE}=32.20 \%)$

I would describe myself as self-confident.

I feel confident of my appearance. $\quad .76$

$\begin{array}{ll}\text { I am good at approaching other people at social functions. } & .70\end{array}$

I enjoy social gatherings just to be with people. $\quad .78$

I always try to look straight at people when I talk to them. $\quad .73$

I have no doubts about my social competence. $\quad .76$

Social expression confidence $(\alpha=.79 ; \mathrm{EV}=2.09 ; \mathrm{VE}=$

$12.27 \%)$

I am not likely to speak to people until they speak to me. ${ }^{\circledR}$

When in a group of people, I have trouble thinking of the right things to say. ${ }^{\circledR}$

When in a group of people, I usually do what the others want

rather than make my own suggestions. ${ }^{\circledR}$

I cannot seem to get others to notice me. ${ }^{\circledR}$ 


\begin{tabular}{lc}
\hline Measurement item & $\begin{array}{c}\text { Factor } \\
\text { loading }\end{array}$ \\
\hline $\begin{array}{l}\text { Social dominance }(\alpha=.62 ; \mathrm{EV}=1.16 ; \mathrm{VE}=6.80 \%) \\
\text { When I'm in a disagreement with other people, my opinion }\end{array}$ & .74 \\
usually prevails. & .87 \\
$\begin{array}{l}\text { I would describe myself as one who tries to feel in control of a } \\
\text { situation. }\end{array}$ & .77 \\
\hline Happiness $(\alpha=.87 ; \mathrm{EV}=2.35 ; \mathrm{VE}=13.85 \%)$ & .84 \\
In most ways my life in the U.S. is close to my ideal. & .85 \\
The conditions of my life in the U.S. are excellent. & .79 \\
I am satisfied with my life in the U.S. & .71 \\
So far I have gotten the important things I want in life in the & \\
U.S. & \\
If I could live my life over, I would change almost nothing. & \\
\hline
\end{tabular}

Note. $\mathrm{EV}=$ Eigenvalue, $\mathrm{VE}=$ Variance Explained, ${ }^{\circledR}$ Reverse coded.

\section{Correlations Among ISAS}

Pearson correlation was additionally run for ISAS to examine the relationships among the four adjustment strains. Academic strains were positively correlated with language $(r=.379, p<.01)$, personal $(r=.488, p$ $<.01)$, and social strains $(r=.440, p<.01)$. Language strains were positively correlated with personal $(r=.381, p<.01)$ and social strains $(r=$ $.300, p<.01)$. Lastly, personal and social strains were positively correlated $(r=.537, p<.01)$ and showed the highest correlation. Therefore, an increase in one dimension of the adjustment strains significantly increased other dimensions.

\section{Hypothesis Testing}

As discussed earlier, because the self-esteem scale was multidimensional in this study, Hypotheses 1 and $3 \sim 4$ were revised as follows:

$\mathrm{H}_{1-1}$ : The higher the ISAS (a. academic, b. language, c. personal, and d. social strains), the lower the international students' social competence.

$\mathrm{H}_{1-2}$ : The higher the ISAS (a. academic, b. language, c. personal, and d. social strains), the lower the international students' social expression confidence. 
$\mathrm{H}_{1-3}$ : The higher the ISAS (a. academic, b. language, c. personal, and d. social strains), the lower the international students' social dominance.

$\mathrm{H}_{3}$ : The lower the international students' self-esteem (a. social competence, b. social expression confidence, and c. social dominance), the lower their happiness.

$\mathrm{H}_{4}$ : The lower the international students' self-esteem (a. social competence, $\mathrm{b}$. social expression confidence, and c. social dominance), the higher their engagement in compulsive online buying.

All hypotheses except for $\mathrm{H} 2$ and $\mathrm{H} 3$ were tested by conducting hierarchical multiple regression analysis to control for the effects of respective covariates. Multiple linear regression analysis was run for $\mathrm{H} 2$ and H3. H1-1 H1-3 proposed the negative effects of four adjustment strains on the three dimensions of self-esteem (i.e., social competence, social expression confidence, and social dominance). Previous studies have shown that men are slightly more positive than women in global self-esteem (Kling, Hyde, Showers \& Buswell, 1999). Therefore, gender was entered as a covariate. Regarding H1-1, the overall model with gender and four adjustment strains was statistically significant $(F=3.141, p<.05)$ and explained $10.1 \%$ of variability in social competence. Gender had no significant effect on social competence $(\beta=.043, p=.601)$. Among the four strains, social strains showed a significant negative effect on social competence $(\beta=-.309, p<.01)$ (Table 3$)$. Therefore, H1-1d was supported, while H1-1a $\sim$ H1-1c were rejected.

Table 3. The effect of ISAS on social competence.

\begin{tabular}{lccccc}
\hline Variable & $\beta$ & $t$ & $R$ & $R^{2}$ & $\Delta R^{2}$ \\
\hline Model 1 (Covariate) & & & .026 & .001 & \\
$\quad$ Gender & .026 & .315 & & & \\
Model 2 (Overall) & & & .318 & .101 & .100 \\
$\quad$ Gender & .043 & .525 & & & \\
Academic strains & .073 & .749 & & & \\
Language strains & -.145 & -1.623 & & & \\
Personal strains & .069 & .653 & & & \\
$\quad$ Social strains & -.309 & $-3.152^{* *}$ & & & \\
\hline
\end{tabular}

Note. ${ }^{* *} p<.01$ 
Table 4. The effect of ISAS on social expression confidence.

\begin{tabular}{llclcc}
\hline Variable & $\beta$ & $t$ & $R$ & $R^{2}$ & $\Delta R^{2}$ \\
\hline Model 1 (Covariate) & & & .006 & .000 & \\
$\quad$ Gender & -.006 & -.072 & & & \\
Model 2 (Overall) & & & .616 & .380 & .380 \\
$\quad$ Gender & .083 & 1.211 & & & \\
$\quad$ Academic strains & -.038 & -.476 & & & \\
$\quad$ Language strains & -.106 & -1.432 & & & \\
$\quad$ Personal strains & -.241 & $-2.759^{* *}$ & & & \\
$\quad$ Social strains & -.385 & $-4.175^{* * *}$ & & & \\
\hline
\end{tabular}

Note. ${ }^{* *} p<.01, * * * p<.001$

Regarding H1-2, the overall model with gender and four adjustment strains was significant $(F=17.150, p<.001)$ and explained $38 \%$ of variability in social expression confidence. Gender was not significant $(\beta=$ $.083, p=.942)$. Social strains $(\beta=-.385, p<.001)$ and personal strains $(\beta=$ $-.241, p<.01)$ showed significant negative effects on social expression confidence (Table 4). Therefore, H1-2c and H1-2d were supported, while H1-2a and H1-2b were rejected. Regarding H1-3, the overall model with gender and four adjustment strains was not significant $(F=.881, p=.495)$ and explained only $3.10 \%$ of variability in social dominance. None of these variables significantly influenced social dominance. Therefore, H1-3 was rejected.

H2 proposed the negative effects of four adjustment strains on happiness. The overall model with four adjustment strains was statistically significant $(F=6.168, p<.001)$ and explained $14.90 \%$ of the variability in happiness. Specifically, language strains $(\beta=-.190, p<.05)$ and personal strains $(\beta=-.240, p<.05)$ showed significant negative effects on happiness (Table 5). Therefore, $\mathrm{H} 2 \mathrm{~b}$ and $\mathrm{H} 2 \mathrm{c}$ were supported, while $\mathrm{H} 2 \mathrm{a}$ and $\mathrm{H} 2 \mathrm{~d}$ were rejected.

Table 5. Result of multiple regression analysis for the effect of ISAS on happiness.

\begin{tabular}{lcccc}
\hline Variable & $\beta$ & $t$ & $B$ & $R^{2}$ \\
\hline & & & & .149 \\
Academic strains & -.083 & -.880 & -.079 & \\
Language strains & -.190 & $-2.190^{*}$ & -.160 & \\
Personal strains & -.240 & $-2.412^{*}$ & -.196 & \\
Social strains & -.045 & .469 & .044 & \\
\hline
\end{tabular}

Note. ${ }^{*} p<.05$ 
H3 proposed the positive effects of three dimensions of self-esteem on happiness. The overall model with three dimensions of self-esteem was significant $(F=13.809, p<.001)$ and explained $22.60 \%$ of variability in happiness. Specifically, social competence positively affected happiness ( $\beta$ $=.475, p<.001$ ), whereas the other two dimensions were not significant (Table 6). Therefore, H3a was supported, while $\mathrm{H} 3 \mathrm{~b}$ and $\mathrm{H} 3 \mathrm{c}$ were rejected.

$\mathrm{H} 4$ and $\mathrm{H} 5$ proposed the negative effects of self-esteem and happiness on engagement in compulsive online buying. Women and people with a higher income are more likely to engage in compulsive buying than are men and people with a lower income (Dittmar, 2005), and materialism and impulsive buying tendency are positively related to compulsive buying (Billieux et al., 2008; Dittmar, 2005). Therefore, gender, income, materialism, and impulsive buying tendency were entered as covariates. The result showed that the model with the four covariates was significant $(F=$ $20.105, p<.001)$ and accounted for $36.30 \%$ of variability in compulsive online buying. The overall model with three self-esteem dimensions, happiness, and four covariates was significant $(F=10.680, p<.001)$ and explained $38.4 \%$ of variability in engagement in compulsive online buying. This overall model showed $2.10 \%$ improvement in variability. Impulsivity was a significant covariate $(\beta=.541, p<.001)$. Social expression confidence was marginally significant at the $90 \%$ confidence level and negatively affected engagement in compulsive online buying $(\beta=-.130, p=$ $.072)$. Social competence $(\beta=-.037, p=.660)$, social dominance $(\beta=-.020$, $p=.785)$, and happiness $(\beta=.087, p=.264)$ were not significant (Table 7). Therefore, $\mathrm{H} 4$ and $\mathrm{H} 5$ were rejected, except for $\mathrm{H} 4 \mathrm{~b}$, which was marginally significant.

Table 6. The effect of self-esteem on happiness.

\begin{tabular}{lcccc}
\hline Variable & $\beta$ & $t$ & $B$ & $R^{2}$ \\
\hline & & & & .226 \\
Social Competence & .475 & $5.895^{* * *}$ & .513 & \\
Social Expression & .049 & .633 & .050 & \\
Confidence & & & & \\
Social Dominance & -.107 & -1.376 & -.121 & \\
\hline
\end{tabular}

Note. $* * * p<.001$ 
Table 7. The effect of self-esteem and happiness on compulsive online buying.

\begin{tabular}{lccccc}
\hline Variable & $\beta$ & $t$ & $R$ & $R^{2}$ & $\Delta R^{2}$ \\
\hline Model 1 (Covariate) & & & .603 & .363 & \\
$\quad$ Gender & .104 & 1.552 & & & \\
Income & -.103 & -1.526 & & & \\
$\quad$ Materialism & .040 & .408 & & & \\
$\quad$ Impulsivity & .566 & 5.747 & & & \\
Model 2 (Overall) & & & .620 & -.384 & .021 \\
$\quad$ Gender & .107 & 1.571 & & & \\
Income & -.112 & -1.656 & & & \\
Materialism & .062 & .625 & & & \\
Impulsivity & .541 & $5.436^{* * *}$ & & & \\
$\quad$ Social competence & -.037 & -.441 & & & \\
$\quad$ Social expression & & & & & \\
confidence & -.130 & $-1.816 \dagger$ & & & \\
$\quad$ Social dominance & & & & \\
$\quad$ Happiness & -.020 & -.273 & & \\
& .087 & 1.122 & & & \\
\end{tabular}

Note. ${ }^{\dagger} p<.10, * * * p<.001$

H6 proposed the positive effects of four adjustment strains on engagement in compulsive online buying. The results showed that the model with four covariate variables (gender, income, materialism, and impulsivity) was significant $(F=20.105, p<.001)$ and accounted for $36.30 \%$ of variability in compulsive online buying. The overall model with four adjustment strains and four covariates was significant $(F=11.911, p<.001)$ and explained $41.00 \%$ of variability in compulsive online buying. The overall model showed improvement in variability by $4.70 \%$. Specifically, impulsivity was a significant covariate $(\beta=.523, p<.001)$ and income was marginally significant at the $90 \%$ confidence level $(\beta=-.115, p=.088)$. However, in contrast with previous findings, income negatively affected engagement in compulsive online buying: respondents with a lower income showed slightly higher engagement. When the significant effects of impulsivity and income were controlled for, social strains still positively affected compulsive online buying $(\beta=.182, p<.05)$ (Table 8). Therefore, H6a $\sim$ H6c were rejected and H6d was supported. Figure 1 demonstrates the significant results of the hypothesis testing. 
Table 8. The effect of ISAS on compulsive online buying.

\begin{tabular}{lccccc}
\hline Variable & $\beta$ & $t$ & $R$ & $R^{2}$ & $\Delta R^{2}$ \\
\hline Model 1 (Covariates) & & & .603 & .363 & \\
$\quad$ Gender & .104 & -.672 & & & \\
Income & -.103 & & & & \\
Materialism & .040 & & & & \\
$\quad$ Impulsivity & .566 & & .640 & .410 & .047 \\
Model 2 (Overall) & & & & \\
$\quad$ Gender & .073 & 1.078 & & & \\
Income & -.115 & $-1.716^{\dagger}$ & & & \\
Materialism & .020 & .202 & & & \\
Impulsivity & .523 & $5.319^{* * *}$ & & & \\
Academic Strains & -.014 & -.169 & & & \\
Language Strains & -.006 & -.077 & & & \\
Social Strains & .182 & $2.195^{*}$ & & & \\
Personal Strains & .082 & .938 & &
\end{tabular}

Note. ${ }^{\dagger} p<.10,{ }^{*} p<.05,{ }^{* * *} p<.001$

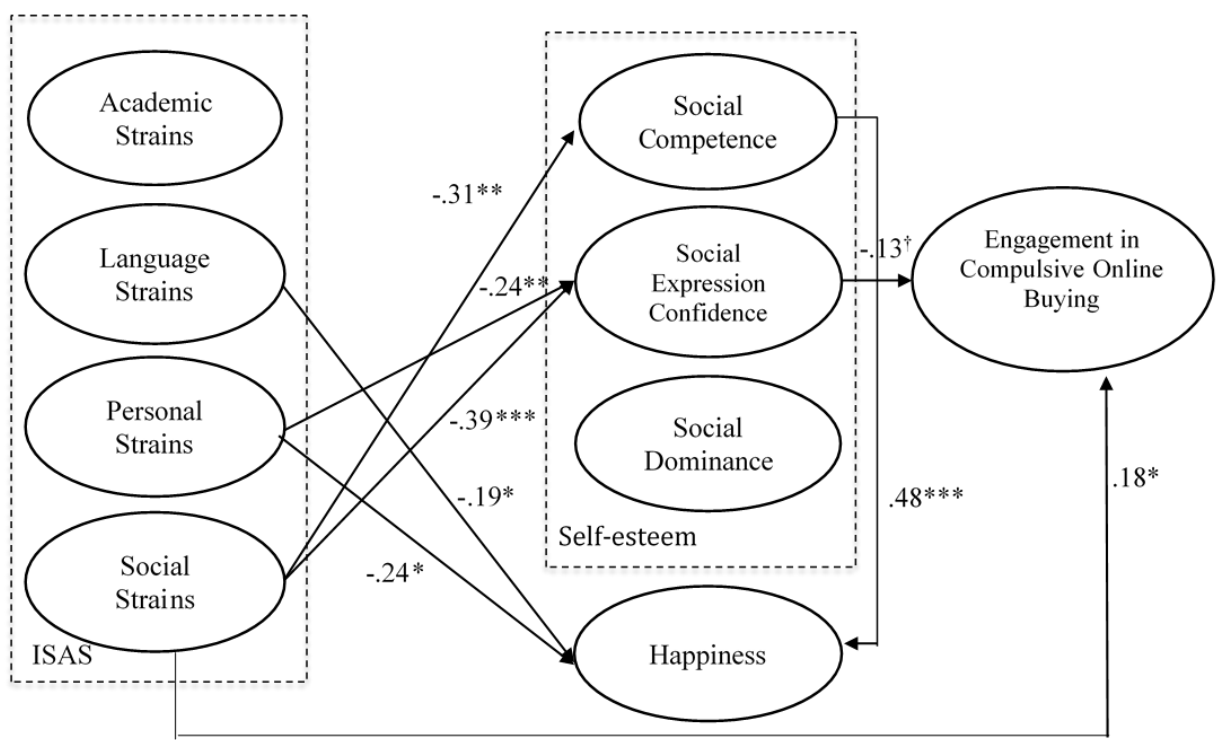

Figure 1. Results of hypotheses testing note. ${ }^{\dagger} p<.10,{ }^{*} p<.05,{ }^{* *} p<.01$, $* * * p<.001$. 


\section{DISCUSSION AND CONCLUSIONS}

We examined the extent to which adjustment strains faced by international students reduced self-esteem and happiness and how these factors impacted engagement in compulsive online buying. First, we found that social strains significantly reduced international students' social competence and social expression confidence, which are dimensions of self-esteem. Social strains arise from trouble interacting with people and understanding morals and male/female relationships. International students' social strains caused by trouble with interacting with groups of people may indicate their lack of confidence as members of a minority group in the U.S. (Schmitt et al., 2003). Such devalued identity among international students in turn triggers negative experiences such as feelings of sadness and low self-esteem (Kim, 2001). This study implies that social strains experienced in a foreign culture reduce international students' social interactions by creating social anxiety (Yang, Noels, \& Saumure, 2006), which significantly weakens competence in their social circles and confidence in expressing their opinions. In addition, we found that personal strains, which arise from feelings of loneliness, homesickness, and depression, significantly lowered social expression confidence. Given our findings that personal strains are positively correlated with academic, social, and especially language strains, personal problems associated with language barriers and difficulties with academics and social relationships significantly damaged international students' self-esteem by lowering social expression confidence.

Furthermore, we found that international students' happiness was determined by language and personal strains and social competence. Higher language and personal strains and higher social incompetence led to unhappiness. These findings reiterate that language is a critical barrier to international students' social interactions and happiness (Chen, 1999; Smith $\&$ Khawaja, 2011). This finding generally supports the idea that self-esteem determines psychological well-being (Furnham \& Cheng, 2000; Nesdale \& Mak, 2003; Rosenberg et al., 1995). More specifically, this finding supports previous studies which showed that international students with less successful relationships in their social circles (i.e., low social competence), tended to experience more loneliness and homesickness (Smith \& Khawaja, 2011) as well as more depression (Wehrly, 1988) than did those with more successful relationships. Thus, developing positive self-esteem through strong social competence is critical for international students' happiness in a foreign culture. 
Third, even after controlling for the highly significant influence of impulsive buying tendency (covariate) on compulsive online buying, we found a marginally significant relationship between social expression confidence and compulsive online buying. When international students have lower self-esteem due to the lack of social expression confidence, they tend to engage in compulsive online buying to recover their devalued identify. Similarly, we found that after controlling for the significant impact of impulsivity and the marginal influence of income, international students' social strains triggered compulsive online buying. These findings imply that psychological problems associated with social interactions (e.g., high social strains, low social expression confidence, and social exclusion) tend to drive people to spend and consume more (Mead, Baumeister, Stillman, Rawn \& Vohs, 2011).

\section{IMPLICATIONS}

This study contributes to the higher education and compulsive buying literature by empirically investigating the underlying psychological mechanism of international students' spending behavior driven by adjustment strains in the U.S. This study demonstrated that international students' strains are related to low self-esteem, unhappiness, and high engagement in compulsive online buying. Our findings suggest that one of the most fundamental ways to solve many of international students' problems is to enhance their language skills. International students' language barriers tend to create social anxiety (Yang et al., 2006), which in turn limits opportunities to improve language skills. Social interactions both improve international students' language and social communication skills and reduce personal strains, such as feelings of loneliness, homesickness, and depression. Improving these skills will further enhance their self-esteem and happiness during the adjustment process. Moreover, social strains and social expression confidence were significant drivers of compulsive online buying, suggesting that high social strains and low social expression confidence may signal rising problems with international students' spending behavior.

We demonstrate the need for universities and colleges to develop programs or policies to help international students better adjust to the U.S. academic and social systems, and to identify and reduce problems such as psychological impairment and compulsive consumption behavior in the early stages. Given that younger consumers tend to have more frequent access to the Internet, making it easier to engage in negative consumption 
behavior (Manchiraju et al., 2016), the development of early interruption programs is strongly recommended. For example, higher education institutions may use the scales used in this study to periodically measure ISAS, self-esteem, and happiness and to identify any decreases in the scores. In addition, organizations for international students could provide free conversation partners or tutoring services on an individual or small group basis to help the students improve English skills and social skills, or develop social activities or cultural events to get international students actively involved in social interactions. University residence halls could also consider an international roommate-pairing program to improve international students' academic success and life satisfaction (Tolman, 2017). Furthermore, educators can use group assignments to naturally encourage international students to interact with students of other nationalities. Teachers and academic advisors can help international students better adjust by paying close attention to their academic performance and social relationships. Most importantly, international students should realize the importance of social interaction and the negative consequences of social isolation when studying in a foreign culture, and should learn how to actively cope with cultural shock and adjustment strains. International students are highly encouraged to take advantage of supporting programs, events, or activities offered to them by the university or community.

This study has several limitations. Due to the relatively small sample size, some relationships may have appeared marginally significant or nonsignificant. In addition, we used a convenience sample of students in a university, limiting the generalizability of the findings. Also, the majority of the respondents in this study were from Asia, particularly China. Although $76 \%$ of international students in the U.S. are from Asian countries (U.S. Immigration and Customs Enforcement, 2015), the generalizability of the study findings is limited because of the lack of non-Asian respondents. Future studies may test the proposed relationships with students with more diverse nationalities and more balanced groups of respondents. Lastly, the samples were mainly graduate students. Future research may target undergraduate students and investigate whether there are any differences in perceptions between undergraduate and graduate students.

\section{REFERENCES}

Atalay, A. S., \& Meloy, M. G. (2011). Retail therapy: A strategic effort to improve mood. Psychology \& Marketing, 28(6), 638-659. doi: 10.1002/mar.20404 
Barratt, M. F., \& Huba, M. E. (1994). Factors related to international undergraduate student adjustment in an American community. College Student Journal, $39,422-435$.

Baumeister, R. F., DeWall, C. N., Mead, N. L., \& Vohs, K. D. (2008). Social rejection can reduce pain and increase spending: Further evidence that money, pain, and belongingness are interrelated. Psychological Inquiry, 19(3-4), 145-147. doi: 10.1080/10478400802592307

Billieux, J., Rochat, L., Rebetez, M. M. L., \& Van der Linden, M. (2008). Are all facets of impulsivity related to self-reported compulsive buying behavior? Personality and Individual Differences, 44(6), 1432-1442. doi: 10.1016/j.paid.2007.12.011

Chen, C. P. (1999). Professional issues: Common stressors among international college students: Research and counseling implications. Journal of College Counseling, 2(1), 49-65.

Christenson, G. A., Faber, R. J., De Zwaan, M. D., \& Raymond, N. C., Speaker, S. M., Ekern, M.D., ... \& Echert, E.D. (1994). Compulsive buying: Descriptive characteristics and psychiatric comorbidity. Journal of Clinical Psychiatry, 55, 5-11.

Crano, S. L., \& Crano, W. D. (1993). A measure of adjustment strain in international students. Journal of Cross-Cultural Psychology, 24(3), 267283.

d'Astous, A., Maltais, J., \& Roberge, C. (1990). Compulsive buying tendencies of adolescent consumers. Advances in Consumer Research, 17(1), 306-312.

DeSarbo, W. S., \& Edwards, E. A. (1996). Typologies of compulsive buying behavior: A constrained clusterwise regression approach. Journal of Consumer Psychology, 5(3), 231-262.

Diener, E. D., Emmons, R. A., Larsen, R. J., \& Griffin, S. (1985). The satisfaction with life scale. Journal of Personality Assessment, 49(1), 71-75.

Dittmar, H. (2005). Compulsive buying - A growing concern? An examination of gender, age, and endorsement of materialistic values as predictors. British Journal of Psychology, 96(4), 467-491. doi: 10.1348/000712605X53533

Dittmar, H., Long, K., \& Bond, R. (2007). When a better self is only a button click away: Associations between materialistic values, emotional and identityrelated buying motives, and compulsive buying tendency online. Journal of Social and Clinical Psychology, 26(3), 334-361. doi: 10.1521/jscp.2007.26.3.334

Edwards-Joseph, A., \& Baker, S. (2012). Themes Caribbean overseas students perceive influence their levels of culture shock. College Student Journal, 46(4), 716-729.

Fisher, S., \& Hood, B. (1987). The stress of the transition to university: A longitudinal study of psychological disturbance, absent-mindedness and vulnerability to homesickness. British Journal of Psychology, 78(4), 425441. 
Flynn, D. M., \& MacLeod, S. (2015). Determinants of happiness in undergraduate university students. College Student Journal, 49(3), 452-460.

Furnham, A., \& Cheng, H. (2000). Perceived parental behaviour, self-esteem and happiness. Social Psychiatry and Psychiatric Epidemiology, 35(10), 463470. doi: 10.1007/s001270050265

Gareis, E., Merkin, R., \& Goldman, J. (2011). Intercultural friendship: Linking communication variables and friendship success. Journal of Intercultural Communication Research, 40(2), 153-171. doi: 10.1080/17475759.2011.581034

Gebhard, J. G. (2012). International students' adjustment problems and behaviors. Journal of International Students, 2(2), 184-193.

Gollwitzer, P. M., Wicklund, R. A., \& Hilton, J. L. (1982). Admission of failure and symbolic self-completion: Extending Lewinian theory. Journal of Personality and Social Psychology, 43(2), 358-371.

Gronmo, S. (1988). Compensatory consumer behavior: Elements of a critical sociology of consumption. In Per Otnes (ed.), The Sociology of Consumption. Atlantic Highlands, NJ: Humanities Press International.

Hanley, A., \& Wilhelm, M. S. (1992). Compulsive buying: An exploration into selfesteem and money attitudes. Journal of Economic Psychology, 13(1), 5-18.

Helmreich, R., \& Stapp, J. (1974). Short forms of the Texas Social Behavior Inventory (TSBI), an objective measure of self-esteem. Bulletin of the Psychonomic Society, 4(5), 473-475.

Institute of International Education (2015). Retrieved from http://www.iie.org/ /media/Files/Corporate/Open-Doors/IEW-FifteenYear-Highlights-v2.ashx

Jordan, M. (2015, March 24). International students stream into U.S. colleges. The Wall Street Journal. Retrieved from http://www.wsj.com/articles/ international-students-stream-into-u-s-colleges-1427248801

Kim, Y. Y. (2001). Becoming intercultural: An integrative theory of communication and cross-cultural adaptation. Thousand Oaks, CA: Sage

Kling, K. C., Hyde, J. S., Showers, C. J., \& Buswell, B. N. (1999). Gender differences in self-esteem: A meta-analysis. Psychological Bulletin, 125(4), 470-500.

Kukar-Kinney, M., Ridgway, N. M., \& Monroe, K. B. (2009). The relationship between consumers' tendencies to buy compulsively and their motivations to shop and buy on the Internet. Journal of Retailing, 85(3), 298-307. doi: 10.1016/j.jretai.2009.05.002

Kukar-Kinney, M., Ridgway, N. M., \& Monroe, K. B. (2012). The role of price in the behavior and purchase decisions of compulsive buyers. Journal of Retailing, 88(1), 63-71. doi: 10.1016/j.jretai.2011.02.004

Kukar-Kinney, M., Scheinbaum, A. C., \& Schaefers, T. (2016). Compulsive buying in online daily deal settings: An investigation of motivations and contextual elements. Journal of Business Research, 69(2), 691-699. doi: 10.1016/j.jbusres.2015.08.021 
Liu, D. W. Y. \& Winder, B. (2014) Exploring foreign undergraduate students' experiences of university. International Journal of Qualitative Studies in Education, 27:1,42-64.

Lu, L., \& Gilmour, R. (2006). Individual oriented and socially oriented cultural conceptions of subjective well-being: Conceptual analysis and scale development. Asian Journal of Social Psychology, 9(1), 36-49. doi: 10.1111/j.1467-839X.2006.00183.x

Manchiraju, S., Sadachar, A., \& Ridgway, J. L. (2016). The compulsive online shopping scale (COSS): Development and validation using panel data. International Journal of Mental Health \& Addiction, 1-15.

Mead, N. L., Baumeister, R. F., Stillman, T. F., Rawn, C. D., \& Vohs, K. D. (2011). Social exclusion causes people to spend and consume strategically in the service of affiliation. Journal of Consumer Research, 37(5), 902-919. doi: $10.1086 / 656667$

Mori, S. C. (2000). Addressing the mental health concerns of international students. Journal of Counseling \& Development, 78(2), 137-144.

National Association of Foreign Student Advisers (2016). Retrieved from http://www.nafsa.org/Policy_and_Advocacy/Policy_Resources/Policy_Tre nds_and_Data/NAFSA_International_Student_Economic_Value_Tool/

Nesdale, D., \& Mak, A. S. (2003). Ethnic identification, self-esteem and immigrant psychological health. International Journal of Intercultural Relations, 27(1), 23-40. doi: 10.1016/S0147-1767(02)00062-7

Nunnally, J. C., \& Bernstein, I. H. (1994). The assessment of reliability. Psychometric Theory, 3(1), 248-292.

O'Guinn, T. C., \& Faber, R. J. (1989). Compulsive buying: A phenomenological exploration. Journal of Consumer Research, 16(2), 147-157.

Poyrazli, S., \& Kavanaugh, P. R. (2006). Marital status, ethnicity, academic achievement, and adjustment strains: The case of graduate international students. College Student Journal, 40(4), 767-780.

Poyrazli, S., \& Lopez, M. D. (2007). An exploratory study of perceived discrimination and homesickness: A comparison of international students and American students. The Journal of Psychology, 141(3), 263-280. doi: 10.3200/JRLP.141.3.263-280

Rick, S., Pereira, B., \& Burson, K. A. (2014). The benefits of retail therapy: Making purchase decisions reduces residual sadness. Journal of Consumer Psychology, 24(3), 373-380. doi: 0.1016/j.jcps.2013.12.004

Roberts, J. A., \& Jones, E. (2001). Money attitudes, credit card use, and compulsive buying among American college students. Journal of Consumer Affairs, 35(2), 213-240. doi: 10.1111/j.1745-6606.2001.tb00111.x

Robins, R. W., Hendin, H. M., \& Trzesniewski, K. H. (2001). Measuring global self-esteem: Construct validation of a single-item measure and the Rosenberg Self-Esteem Scale. Personality and Social Psychology Bulletin, 27(2), 151-161. doi: 10.1177/0146167201272002 
Roccas, S., Horenczyk, G., \& Schwartz, S. H. (2000). Acculturation discrepancies and well-being: The moderating role of conformity. European Journal of Social Psychology, 30(3), 323-334.

Rook, D. W., \& Fisher, R. J. (1995). Normative influences on impulsive buying behavior. Journal of Consumer Research, 22(3), 305-13.

Rosenberg, M., Schooler, C., Schoenbach, C., \& Rosenberg, F. (1995). Global selfesteem and specific self-esteem: Different concepts, different outcomes. American Sociological Review, 60 (1), 141-156.

Rucker, D. D., \& Galinsky, A. D. (2008). Desire to acquire: Powerlessness and compensatory consumption. Journal of Consumer Research, 35(2), 257267. doi: $10.1086 / 588569$

Schmitt, M. T., Spears, R., \& Branscombe, N. R. (2003). Constructing a minority group identity out of shared rejection: The case of international students. European Journal of Social Psychology,33(1), 1-12. doi: 10.1002/ejsp. 131

Searle, W., \& Ward, C. (1990). The prediction of psychological and sociocultural adjustment during cross-cultural transitions. International Journal of Intercultural Relations, 14(4), 449-464.

Smith, R. A., \& Khawaja, N. G. (2011). A review of the acculturation experiences of international students. International Journal of Intercultural Relations, 35(6), 699-713. doi: 10.1016/j.ijintrel.2011.08.004

Tajfel, H. E. (1978). Differentiation between social groups: Studies in the social psychology of intergroup relations. NY: Academic Press.

Tolman, S. (2017). The effects of a roommate-pairing program on international student satisfaction and academic Success. Journal of International Students, 7(3), 522-541. doi: 10.5281/zenodo.570013

Trinh, V. D., \& Phau, I. (2012). A new set of measurements for the materialism scale. In 2012 ANZMAC Annual Conference Proceedings, University of South Australia, Australia.

U.S. Immigration and Customs Enforcement (2015). Retrieved from https:/www.ice.gov/sites/default/files/documents/Document/2015/by-thenumbers.pdf

Wang, K. T., Heppner, P. P., Fu, C. C., Zhao, R., Li, F., \& Chuang, C. C. (2012). Profiles of acculturative adjustment patterns among Chinese international students. Journal of Counseling Psychology, 59(3), 424-436. doi: $10.1037 / \mathrm{a} 0028532$

Wehrly, B. (1988). Cultural diversity from an international perspective, Part 2. Journal of Multicultural Counseling and Development, 16(1), 3-15.

Yang, P. J., Noels, K. A., \& Saumure, K. D. (2006). Multiple routes to crosscultural adaptation for international students: Mapping the paths between self-construal, English language confidence, and adjustment. International Journal of Intercultural Relations, 30(4), 487-506. doi: 10.1016/j.ijintrel.2005.11.010 
Yi, J. K., Lin, J. C. G., \& Kishimoto, Y. (2003). Utilization of counseling services by international students. Journal of Instructional Psychology, 30(4), 333342.

YANA LOU received a Master's degree from the Department of Consumer and Design Sciences at Auburn University. Her major interests include international students' adjustment problems and behaviors in a foreign country and the development of an e-platform for providing solutions and resources for the target population.Email: yzl0095@tigermail.auburn.edu

SANG-EUN BYUN, PhD, is an associate professor in the Department of Retailing at University of South Carolina. Her major research interests lie in the area of consumer psychology and decision making, experiential retailing, corporate social responsibility, and retail industry analysis in the global context. Email: sbyun@mailbox.sc.edu 